Document downloaded from:

http://hdl.handle.net/10251/64650

This paper must be cited as:

Bermúdez Tamarit, VR.; Serrano Cruz, JR.; Piqueras Cabrera, P.; Garcia Afonso, O. (2015). Pre-DPF water injection technique for pressure drop control in loaded wall-flow diesel particulate filters. Applied Energy. 140:234-245. doi:10.1016/j.apenergy.2014.12.003.

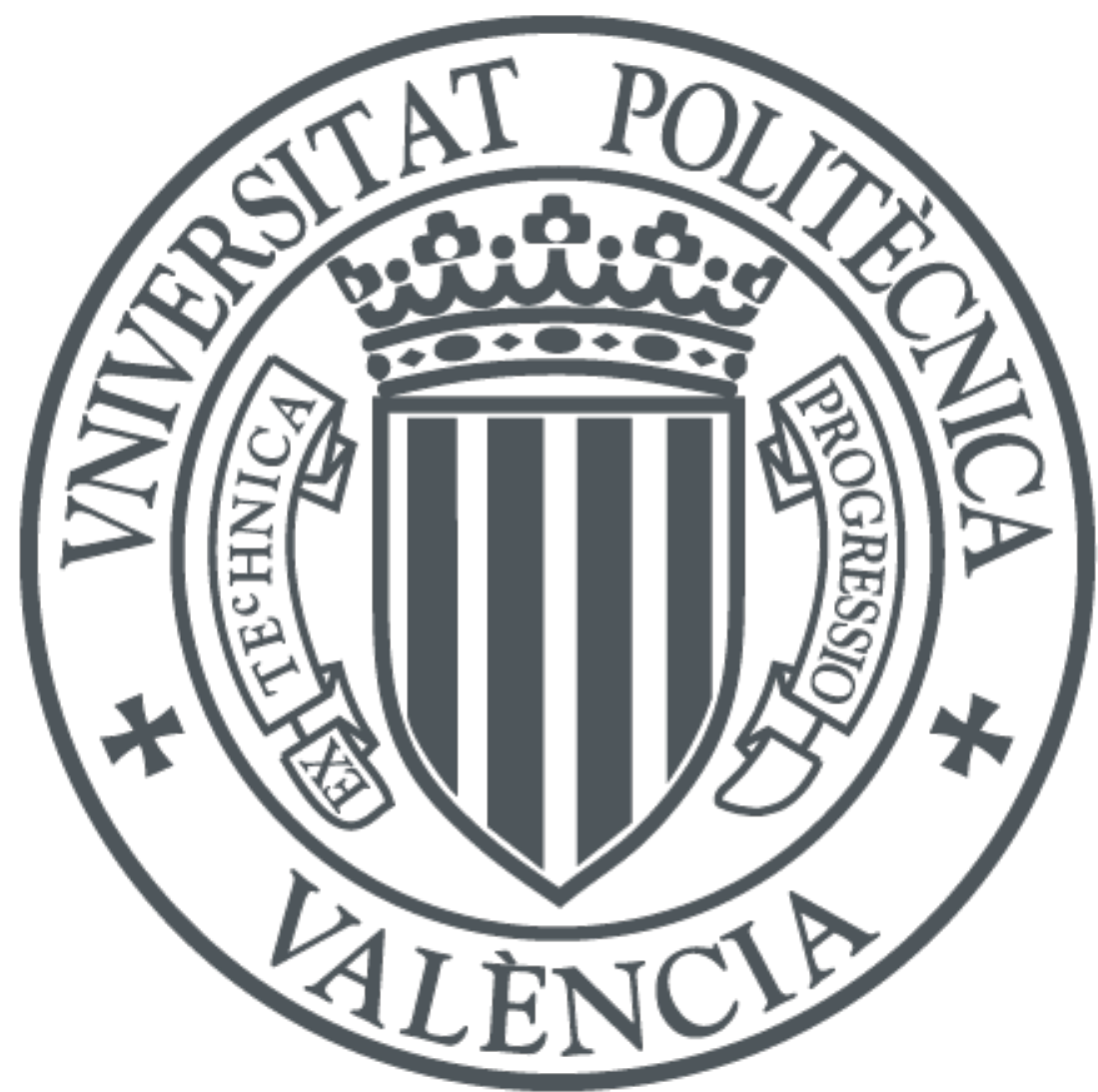

The final publication is available at

http://dx.doi.org/10.1016/j.apenergy.2014.12.003

Copyright Elsevier

Additional Information 


\title{
Pre-DPF water injection technique for pressure drop control in loaded wall-flow diesel particulate filters
}

\author{
V. Bermúdez, J.R. Serrano, P. Piqueras *, O. García-Afonso \\ Universitat Politècnica de València, CMT-Motores Térmicos, Camino de Vera s/n, 46022 Valencia, Spain.
}

\begin{abstract}
Wall-flow type diesel particulate filter (DPF) is a required aftertreatment system for particle emission abatement and standards fulfilment in Diesel engines. However, the DPF use involves an important flow restriction, especially as the substrate gets soot and ash loaded. It gives as a result the increase of the exhaust back-pressure and hence a fuel consumption penalty. The increasing damage of fuel consumption with DPF soot loading leads to the need of the regeneration process. Usually based on active strategies, this process involves an additional fuel penalty but prevents from excessive DPF pressure drop and ensures secure soot burnt out.

Under this context, new solutions are required to improve the state of the art DPF soot loading to pressure drop ratio. This paper presents a novel technique based on pre-DPF water injection to reduce the DPF pressure drop under soot loading conditions by disrupting its dependence on soot/ash loading. It provides benefits to engine fuel economy and also higher flexibility for DPF regeneration and maintenance. The work covers a test campaign performed in a passenger car turbocharged Diesel engine equipped with a wall-flow DPF. The main objective is to describe the technique, to provide a figure of its potential for pressure drop control and fuel consumption reduction. The results of the experiments also confirm soot and ash loading capacity increase and demonstrate the lack of negative effects on filtration efficiency and active and passive regeneration.

Keywords: Diesel engines, diesel particulate filter, water injection, pressure drop, fuel penalty
\end{abstract}

\section{Introduction}

Emission standards in US, Europe and Japan, which are being progressively adopted elsewhere, have forced the manufacturers to make use of several aftertreatment devices as effective way to comply with the stringent limits for gaseous and particle emissions. The diesel particulate filter (DPF) is currently the usual aftertreatment system in Diesel engines for soot particle abatement in passenger, heavy-duty and non-road vehicles [1].

Among different filter solutions, wall-flow monoliths are the DPF type showing the best balance between filtration efficiency and pressure drop performance. While flow-through filters, such as ceramic foams, open honeycomb struc-

${ }^{*}$ P. Piqueras. CMT-Motores Térmicos, Universitat Politècnica de València, Camino de Vera s/n, 46022 Valencia, Spain. Phone: +34 963877650 Fax: +34 963877659 e-mail: pedpicab@mot.upv.es 
tures, metallic wire-mesh or metal-wools, are characterized by low pressure drop, its soot and ash capacity is reduced and the filtration efficiency is low $(40-70 \%)$ [2] against transport application requirements. By contrast, wall-flow DPFs exhibit very high filtration efficiency which is over 95\% even for the ultrafine particles emitted by Diesel engines [3]. This sort of monolithic filters consists of a bundle of small axial parallel channels, which are of small and, typically, square cross-section. Adjacent channels are alternatively plugged at each end, so that the gas enters into the monolith through the open channels in the inlet monolith cross-section (inlet channels). Gas finds the end of inlet channels closed, so that it is forced to flow across the porous wall of the ceramic substrate being the particulate matter filtrated. The flow goes into the outlet channels and finally leaves the monolith.

The pressure drop across the DPF has a negative impact on the engine fuel economy [4]. The DPF pressure drop, which sets the exhaust back-pressure by means of its interaction with the turbine pressure ratio in post-turbo aftertreatment placement [5], increases the pumping work and hence the required injected fuel mass to reach the demanded engine output [6]. The impact of the DPF pressure drop becomes more negative as soot and ash particles are collected in the porous substrate [7].

In this regard, the dynamics and structure of the particle deposition is of great influence on the pressure drop produced by the DPF both concerning soot [8] and ash [9]. In the specific case of ash, its accumulation mixed with soot particles has been proven to form a particulate layer on the porous wall which involves a great pressure drop increase [10]. This damage on pressure drop is reduced when ash deposition takes place in the rear part of the inlet channels due to the ash particle re-entrainment during engine operation [11], despite the lower inlet channel length [12]. These results point out that if such a re-distribution of the particulate matter towards the end plug of the inlet channels could be intentionally caused under a controlled process, for example by injecting a liquid flow able to drag particle deposits, the DPF pressure drop might be reduced and even limited to a desired value.

An additional source of fuel penalty of DPF is the need of regeneration. Most of the operating region in Diesel engine seldom reaches the temperature required to promote the spontaneous soot oxidation $\left(500-600{ }^{\circ} \mathrm{C}\right)$ [13]. Consequently, the DPF regeneration must be forced from a certain level of soot loading involving an additional fuel consumption penalty. The active regeneration events avoid unacceptable levels of exhaust back-pressure due to soot accumulation. Additionally, the regeneration management based on soot mass helps to prevent from uncontrolled regeneration. These processes and an excess of soot mass can lead to DPF structural damage due to high peak of temperature. Despite the efforts for the development of alternative strategies, like $\mathrm{NO}_{2}$ assisted passive regeneration [14], fuel-borne catalysts [15], active non-thermal plasma techniques [16], including ozone injection [17], or the use of induction heating [18], most of the manufacturers are using late fuel injection as the most effective way to promote the soot oxidation [19]. Nevertheless it still entails a further increase of the fuel consumption [20]. Although this damage is periodical and difficult to be assessed [21], the study of Noguchi et al. [22] estimated a decrease of the fuel efficiency between $2 \%$ and $4.5 \%$ during engine operation because of the effect of the regeneration process. To get these results consecutive runs of chassis dynamometer test cycles were performed in three different vehicles (one 2-ton cargo truck and two passenger vehicles). The tests covered driving cycles EPA Highway Fuel Economy Test (HWFET), Tokyo 
Metropolitan Government 2 (TMG-2) and the Japanese JE05 (heavy-duty vehicle) and JC08 (passenger vehicles). The quantification of the fuel penalty due to the regeneration process assuming it occurs throughout the cycle reported a decrease of the fuel efficiency between $31 \%$ and $52.3 \%$ with respect to a cycle without regeneration. These results and variability, which are depending on the regeneration strategy and driving cycle, are similar to the conclusions obtained by Tourlonias and Koltsakis [20], who applied a modelling approach to analyse the regeneration fuel penalty. In this work a fuel consumption increase between $16 \%$ and $21 \%$, as a function of the regeneration strategy, was obtained during a New European Driving Cycle (NEDC) in which was taking place the DPF regeneration. Besides the fuel economy penalty, active regeneration based on in-cylinder fuel post-injection can affect the DPF durability [23] and produce lubricant oil dilution resulting in increased engine wear and the need of frequent maintenance [24].

The current work presents a novel technique based on pre-DPF water injection to reduce and control the DPF pressure drop under soot loading conditions. This technique pursues the need to reduce the DPF pressure drop, its dependence with the soot loading and the regeneration influence on the engine operation and performance. The consequence is the reduction in fuel consumption and $\mathrm{CO}_{2}$ emission. Additionally, such a pressure drop control leads to increase the soot and ash accumulation capability of the monolith. It gives as a result the delay of the required active regeneration event, which can be directly managed based on soot mass loading control avoiding pressure drop issues. Concerning ash loading, the increase of accumulation capacity means the delay of maintenance operations due to this subject. The objective of the work is to describe the basis of the technique from an experimental approach. The experimental campaign covers different type of tests to highlight the feasibility, reliability and robustness of the technique. The pressure drop and fuel consumption control potential is shown in a passenger car engine at the same time that the filtration efficiency and regeneration performance remain unaffected.

\section{Experimental setup}

The tests performed within the scope of this study have been carried out in a turbocharged diesel engine for passenger car use. The main characteristics of the engine are shown in Table 1.

The aftertreatment system is composed of a close-coupled DOC, which is located just at the turbine outlet, and an underfloor DOC followed by the DPF. The tested DPF is an uncoated wall-flow type filter with channels of square cross-section. The main geometrical characteristics of the DPF are shown in Table 2.

\subsection{Test cell setup and instrumentation}

The engine was installed in a test bench equipped with an asynchronous dynamometer able to control engine speed and torque under steady-state and transient operating conditions. The instrumentation accounts for sensors to measure the main magnitudes defining the engine and aftertreatment performance: temperature and mean pressure along the air path, air and fuel mass flow, engine speed, engine torque and turbocharger speed. The sensors are connected to a data acquisition system which controls and synchronises all this information with the ECU and the test cell parameters. Table 3 summarises the main characteristics of the instrumentation. 
As schematically shown in Figure 1, the DPF pressure drop is measured by placing two piezorresistive transducers in the inlet and outlet cones of the DPF. Since the objective is the measurement of mean pressure, these sensors are not cooled but they are connected to the exhaust gas flow through a long duct, in which the flow is kept stopped. It allows transporting pressure disturbances from the measurement point up to the transducer but avoids exposing the sensor to high temperature. The inlet DPF temperature is measured with two K-type thermocouples placed at the top and bottom of the inlet cone. The purpose is to detect if a sudden temperature drop is produced at any of these locations when pre-DPF water is injected. The outlet temperature is measured with one K-type thermocouple placed next to the outlet duct junction.

Concerning the measurement of exhaust gaseous emissions, an Horiba Mexa 6000 F-TIR analyzer was employed to provide a figure of the pollutant emissions downstream of the aftertreatment system. The particle emission was measured with a TSI EEPS (Engine Exhaust Particle Sizer). This spectrometer is able to measure the particle number concentration with a frequency up to $1 \mathrm{~Hz}$ accounting for the particle size distribution in a range between 5.6 to $560 \mathrm{~nm}$. The spectrometer is connected to a valve system allowing the alternative measurement upstream and downstream of the DPF in order to assess the DPF filtration efficiency.

Finally, a by-pass system with two electrovalves was placed upstream of the aftertreatment system. This system, which is shown in Figure 2, was considered due to the need to know the soot mass loading in the DPF at the beginning of every test. During the engine stabilisation the valve in the aftertreatment branch is completely closed and the bypass valve controls the tailpipe exhaust pressure. It is set to the same order of magnitude than the value imposed by the aftertreatment. When the engine is operating under steady-state conditions the aftertreatment valve is completely open and the by-pass valve closed. This procedure does not avoid the DPF thermal transient from one operating point to another but removes the influence of the DPF soot loading increase because of filtration during the thermal stabilisation phase.

\subsection{Types of tests}

Different tests were considered in order to assess the pre-DPF water injection technique in a representative range of operating conditions:

- Water injection settings analysis with $22 \mathrm{~g}(8 \mathrm{~g} / \mathrm{l})$ of DPF soot loading and engine running under steady-state operating conditions at $2500 \mathrm{rpm}, 28 \%$ in engine load and EGR rate of $16 \%$.

- DPF soot loading tests under steady-state conditions at $2500 \mathrm{rpm}, 28 \%$ engine load and EGR rate of $16 \%$. This kind of tests allows demonstrating with a simple approach the ability of the pre-DPF water injection technique to control the pressure drop value independently of the soot loading. Two different types of soot loading tests were performed being each of them repeated under baseline DPF conditions and the use of pre-DPF water injection. One of the tests ended with $60 \mathrm{~g}(22 \mathrm{~g} / \mathrm{l})$ of soot loading. This value was selected based on the original trigger of the tested engine for active regeneration initiation, which is shown in Figure 3. The DPF pressure drop is also 
represented in Figure 3 as a function of the volumetric flow rate at DPF inlet during the baseline soot loading tests. In the case of the soot loading test up to $60 \mathrm{~g}$ of soot loading the pre-DPF water injection begins to be applied from $30 \mathrm{~g}(11 \mathrm{~g} / \mathrm{l})$. In the other test the pre-DPF water injection began at $9 \mathrm{~g}(3.3 \mathrm{~g} / \mathrm{l})$ and the loading continued up to $30 \mathrm{~g}(11 \mathrm{~g} / \mathrm{l})$. The maximum loading for this second test agrees with the value commonly accepted as high soot loading to promote active regeneration [25] because of excessive pressure drop and hence fuel penalty $[19,26]$. In fact, although the optimum soot loading to perform active regeneration reducing fuel penalty depends on the specific strategy [20], studies performed by Singh et al. [27] found the optimum soot loading in $5.5 \mathrm{~g} / 1$ to limit the fuel penalty due to excessive pressure drop. This low value strengthens the interest for pressure drop limitation at the same time that the active regeneration is delayed to high soot loading values.

- After the DPF soot loading up to $60 \mathrm{~g}$ in soot mass under baseline and pre-DPF water injection conditions, the engine was subjected to additional tests consisting of driving cycles. The tests comprise two consecutive NEDCs, which will be referred as cold and hot NEDC respectively. The purpose is to widen the operating conditions in which the pressure drop reduction brought by the pre-DPF water injection is verified. Hence, higher consistency in fuel consumption reduction assessment is obtained. During these tests the pre-DPF water injection technique was not applied. The DPF was tested with the conditions reached once finished the DPF soot loading.

- After loading the DPF with $30 \mathrm{~g}$ in soot mass under baseline and pre-DPF water injection conditions, the engine was subjected to motoring tests at different engine speeds. Next, the engine was run under steady-state operating conditions at low engine load. These tests provided an additional figure of the DPF pressure drop reduction and fuel economy effect. Analogously to NEDC cycles, during these tests the pre-DPF water injection technique was not applied and the DPF was tested with the conditions reached at the end of the corresponding DPF soot loading test.

- Finally, the behavior of the DPF pressure drop dynamics is analysed during a regeneration process performed applying an active strategy based on fuel post-injection.

\section{Water injection settings}

Although the optimization of the water injection procedure is not the main objective of this work, a rough exploration of injection requirements was performed. It provides a suitable reference for the application of the technique in the different tests described in this work.

The water flow injected at the inlet of the DPF (Figure 1) is controlled by means of an electronic valve. The quantity of injected water mass and the volumetric flow rate are set by means of the nozzle diameter, the injection pressure and a timer coupled to the electronic valve. The injector used in the study was a simple calibrated orifice nozzle. Three different nozzle diameters were considered: 4, 2.7 and $1 \mathrm{~mm}$. 


\subsection{Effect of quantity of injected water mass}

Firstly the effect of the total quantity of injected water mass is analysed. During these tests the water tank was pressurised (injection pressure) to 1.5 bar and the nozzle diameter set to $4 \mathrm{~mm}$ what provides an injection rate of $66 \mathrm{~g} / \mathrm{s}$. Consequently the volumetric flow rate was kept constant. The duration of the injection event is regulated in order to control the injected water mass.

Figure 4 shows the results in DPF pressure drop and temperature variation during different injection events defined by the injected water mass: $200 \mathrm{~g}, 110 \mathrm{~g}, 85 \mathrm{~g}$ and $40 \mathrm{~g}$. Table 4 indicates the change in injection duration to provide the required water mass in every case. In all cases the DPF soot loading is $8 \mathrm{~g} / \mathrm{l}(22 \mathrm{~g})$ and the engine operating point is defined by $2500 \mathrm{rpm}$ in engine speed, $28 \%$ in engine load and a EGR rate of $16 \%$. The vertical dashed lines point out the beginning of the injection process and the horizontal traces the change in pressure drop. The change in pressure drop due to the water injection process is defined as the change in pressure drop between the beginning of the injection event and the end of the thermal transient caused by the water flow.

Column (a) in Figure 4 represents the DPF pressure drop and the inlet and outlet gas temperature during the water injection event, which lasted $3 \mathrm{~s}$ to inject $200 \mathrm{~g}$. When the injection starts, the DPF inlet and outlet temperature drops instantaneously. It causes the sudden DPF pressure drop reduction because of the gas density increase and velocity reduction. Some seconds after the injection process has ended, the DPF inlet temperature recovers its nominal value given by the engine operating conditions. As a consequence, the DPF pressure drop increases again slowly in a process that is also controlled by the DPF inner temperature. The DPF outlet temperature is below the initial value for a longer time due to the water residence time inside the DPF monolith and the thermal inertia produced by its presence. This transient process is considered to be finished when the DPF oulet temperature reaches the value at the beginning of the water injection event. The DPF pressure drop plotted in column (a) shows that the water injection process has brought a decrease in the initial pressure drop, which for this event has been close to $1500 \mathrm{~Pa}$. It represents a reduction higher than $11.5 \%$ with respect to the initial pressure drop. This result is not due to soot emission release, as it will be justified forward in Section 6.1. The cause lies in the restructuring of the soot deposits in the particulate layer and inside the porous substrate. Although there are not empirical evidences based on optical analysis, water droplets are supposed to drag soot particles towards the end of the inlet channels thus reducing the particulate layer thickness in the vicinity of the channel inlet. It produces the pressure drop reduction. Additionally, water flowing through the porous wall between inlet and outlet channels may increase the thickness of penetration of the soot what causes permeability increase [28]. These hypotheses are discussed and strengthened in following sections with additional experimental data.

The reduction of the quantity of injected water mass gives as a result a lower drop in gas temperature across the DPF reducing the duration of the thermal transient process. However, lowering the mass of injected water keeping the water flow rate also reduces the positive effect concerning pressure drop decrease once the thermal transient has finished. As column (b) in Figure 4 depicts, when the injected water mass is reduced to $110 \mathrm{~g}$ the benefit in pressure drop decrease is scarcely arriving to $400 \mathrm{~Pa}$. No effects on pressure drop are found below $85 \mathrm{~g}$ of injected water mass. 
Therefore, under the constraint of the available injection pressure, it is possible to consider the quantity of $200 \mathrm{~g}$ of water mass as the minimum amount of water required to obtain an effective exhaust back-pressure reduction. Under engine operating conditions, the origin of the injected water can be of diverse nature including external source or condensate collected from several sources in the engine or the vehicle [29].

\subsection{Effect of the injector nozzle diameter}

Taking as baseline $200 \mathrm{~g}$ of injected water mass, the effect of the nozzle diameter on the pressure drop decrease is assessed. As the injection pressure is not varied, this approach is equivalent to evaluate the water injection rate influence. Table 5 summarises the change in injection rate and duration to provide $200 \mathrm{~g}$ of water mass as a function of the nozzle diameter.

Figure 5 shows the effect of the nozzle diameter on the DPF pressure drop and the temperature profile throughout the injection process. Results in column (a) correspond to the test with $4 \mathrm{~mm}$ in nozzle diameter. It is an equivalent test to that shown in Figure 4(a). The injection rate is $66 \mathrm{~g} / \mathrm{s}$. A reduction in nozzle diameter up to $2.7 \mathrm{~mm}$, whose test is shown in column (b) of Figure 5, reduces the injection rate to $18 \mathrm{~g} / \mathrm{s}$. However, there is not a relevant effect on the pressure drop reduction, which is kept close to $1500 \mathrm{~Pa}$.

The main differences concern the temperature profile. The analysis of the DPF outlet temperature reveals that the thermal transient duration due to the water injection increases as the injection rate is reduced. The causes are the increase of the water injection duration and the lower jet momentum. Its decrease produces that part of the water mass accumulates at the DPF inlet cone instead of penetrating directly into the inlet channels with the gas stream. This process explains the low temperature measured by the thermocouple placed at the bottom of the DPF inlet cone during more than $80 \mathrm{~s}$. When the nozzle diameter is set to $1 \mathrm{~mm}$, whose test results are shown in column (c) of Figure 5, the further decrease in water momentum confirms this phenomenon, which last more than $110 \mathrm{~s}$, but also makes the pressure drop reduction practically disappear due to the low injection rate $(9 \mathrm{~g} / \mathrm{s})$ and the subsequent decrease of the water drag effect.

\section{DPF pressure drop control during loading processes}

The reduction of the pressure drop brought by a single pre-DPF water injection in a soot loaded DPF drives the interest to demonstrate the ability of this technique to control the DPF pressure drop as a function of the particulate matter loading. As explained in Section 2, two DPF loading tests were performed with this purpose. Every test was repeated twice to analyse the engine and DPF performance considering the application or not of pre-DPF water injection.

Figure 6(a) shows the DPF pressure drop profile during the soot loading test up to $60 \mathrm{~g} \mathrm{(22} \mathrm{g/l).} \mathrm{In} \mathrm{the} \mathrm{case} \mathrm{of} \mathrm{pre-}$ DPF water injection the technique begins to be applied from a soot loading of $30 \mathrm{~g}$ and accounts for an injected water mass of $500 \mathrm{~g}$ with a nozzle diameter of $4 \mathrm{~mm}$. The injection rate is $66 \mathrm{~g} / \mathrm{s}$ so that the duration of every injection event 
is $7.5 \mathrm{~s}$. The injections are consecutively performed. Every injection event begins when the pressure drop recovers the value corresponding to the baseline pressure drop at $30 \mathrm{~g}$ of soot loading after the previous injection process.

Similarly, Figure 6(b) shows the DPF pressure drop during the soot loading test up to $30 \mathrm{~g}(11 \mathrm{~g} / \mathrm{l})$. In this test the pre-DPF water injection starts at $9 \mathrm{~g}$ of soot loading and the mass of injected water is set to the minimum required $(200 \mathrm{~g})$ making use of the nozzle diameter of $4 \mathrm{~mm}$. In this case the injection rate and duration coincides with the settings indicated in Section 3 for this injected water mass, i.e. $66 \mathrm{~g} / \mathrm{s}$ and $3 \mathrm{~s}$ respectively. Again, every injection event is performed when the target pressure drop, in this case corresponding to the baseline at $9 \mathrm{~g}$ of soot loading, is reached. The consecutive application of the technique allows the pressure drop to be controlled at a constant level independently of the soot loading.

The overview of the results in the two tests evidences that the target pressure drop can be set to the desired level and controlled during a whole soot loading process. Therefore, there is flexibility to optimise the target pressure drop, i.e. the penalty on brake specific fuel consumption, and the number of required water injection events before reaching a maximum soot loading. In fact, the control on the DPF regeneration becomes completely independent of the soot loading effect on the pressure drop and only dependent on the soot mass accumulated. In the same way, the dependence between the critical ash mass and the pressure drop disappears, what reduces the constraints related to maintenance operations.

Focusing on the DPF soot loading test shown in Figure 6(b), the comparison with the baseline loading process points out an accumulated reduction of $4000 \mathrm{~Pa}$ in pressure drop when the soot loading reaches $30 \mathrm{~g}$. Taking as reference the soot emission during a NEDC in the tested engine, the soot loading would correspond to 86 consecutive NEDCs. Considering that the technique is applied from $9 \mathrm{~g}$ of soot loading, the pressure drop has been controlled in equivalence during 58 consecutive NEDCs, requiring for that purpose 22 injection events. Since the quantity of injected water mass in every injection event is $200 \mathrm{~g}$ it involves a total water consumption of $4.4 \mathrm{~kg}$ during this soot loading test. If this quantity is averaged during the duration of the equivalent NEDCs of engine operation results in $1 \mathrm{~kg}$ of injected water every $13.25 \mathrm{NEDCs}$, what means a water consumption of $0.23 \mathrm{~kg} / \mathrm{h}$. Note that this quantity has not been optimized, especially because of the possibility to improve the injection effectiveness by increasing the water injection pressure. However, it is worth to note that this result is repetitive as concluded from the analysis of the soot loading test up to $60 \mathrm{~g}$ of soot loading shown in Figure 6(a). This test required 12 injection events of $500 \mathrm{~g}$ of water mass to keep constant the DPF pressure drop from $30 \mathrm{~g}$ to $60 \mathrm{~g}$ of soot loading. It results in control of the pressure drop in equivalence during 86 consecutive NEDCs with a total water consumption of $6 \mathrm{~kg}$, i.e. $13.8 \mathrm{NEDCs}$ per kilogram of injected water $(0.22 \mathrm{~kg} / \mathrm{h})$.

With regard to the required number of injections, it must be noted that as the number of injections increases, the effectiveness of every further event decreases. Although all the injection events are defined with the same settings, Figure 6(b) points out that as the process is performed consecutively the soot loading between injections is reduced to keep the target of maximum pressure drop. It means that the time between injection events becomes more and more reduced. 
This phenomenon is sketched in Figure 7, which focuses on the first and the third water injection events during the DPF loading test shown in Figure 6(b). The first injection event provides a pressure drop reduction of $1100 \mathrm{~Pa}$. The second injection takes place after increasing the soot loading in $1.75 \mathrm{~g}(1.93 \mathrm{~g}$ if considered from the injection beginning), which in turns means a soot emission equivalent to 5 NEDCs. However, the DPF pressure drop reduction produced by the third injection event reaches only $900 \mathrm{~Pa}$ being required starting the following injection event after increasing the soot loading $1 \mathrm{~g}$ (1.2 $\mathrm{g}$ if considered from the injection beginning). It means an emission equivalent to 2.9 NEDCs.

Figure 8 plots the evolution of the soot accumulated in the DPF between consecutive injection events throughout the soot loading test shown in Figure 6(b). From the first injection event, the soot loading between two consecutive injections is progressively decreasing up to provide a reduced benefit in the injection event number 14 . The soot loading between the 13th and 14th injection events is $0.54 \mathrm{~g}$ in contrast to the $1.93 \mathrm{~g}$ of soot loading between the $1 \mathrm{st}$ and 2 nd injection events.

The reason explaining the pre-DPF water injection loss of effectiveness is supposed to lie in the fact that all the soot composing the particulate layer is gradually drag towards the inlet channel end. Therefore the particulate layer gets an increasing thickness profile along the inlet channel length. This makes the thickness in the proximity of the channel inlet be thinner. With the initial injection events the resulting length with thin particulate layer is long and thus great the benefit in pressure drop. The filtration velocity profile makes the flow adapt to such a particulate layer thickness. As a result the pressure drop decreases according to the Darcy's law [30] due to the thinner layer without being highly affected by the filtration velocity change. However, as injection events are carried out the thin particulate layer length becomes shorter and the filtration velocity too high in this region, so that the pressure drop benefit comes of lower magnitude.

According to this process, it is proposed to increase the target pressure drop in a low magnitude, but enough to make the particulate layer thickness increase again and become more homogeneous along the inlet channel length. This is what is performed between the injection events 14th and 15th (Figure 8). Between these injections, the target pressure drop is increased from $9500 \mathrm{~Pa}$ to $10000 \mathrm{~Pa}$. Consequently, next injection events recover effectiveness, i.e. higher benefit in pressure drop reduction and hence higher soot loading up to the following injection event. This process is again losing effectiveness progressively up to the last injection event. After it the target pressure drop should be increased again in order to further increase the soot loading under pressure drop control conditions.

Additional tests were performed after finishing the soot loading tests shown in Figure 6 to verify the DPF pressure drop reduction under different operating conditions. Figure 9(a) shows the DPF pressure drop during a cold NEDC performed after loading the DPF with $60 \mathrm{~g}$ (Figure 6(a)). Similarly, Figure 9(b) represents the DPF pressure drop as a function of the engine speed under motoring operating conditions being the DPF soot loading equal to $30 \mathrm{~g}$ (Figure 6(b)). Both tests certify the robustness and consistency of the DPF pressure drop reduction induced by the application of the pre-DPF water injection technique during the loading phase and the consequent restructuring of the soot distribution. Although the benefit in pressure drop is a function of the mass flow through the DPF and the initial 
soot loading from which the described technique is applied, both tests point out a pressure drop reduction ranging around 25\%. This benefit can be increased depending on the DPF characteristics being higher as increases the ash accumulation or the critical soot mass able to be accumulated without damaging the DPF substrate durability during subsequent active or uncontrolled regeneration events.

\section{Ability to reduce fuel consumption}

The reduction in DPF pressure drop due to pre-DPF water injection involves the mitigation of part of the fuel penalty caused by the DPF presence. This mitigation is related to the independence of the pressure drop with respect to the soot-ash loading that is reached. The reduction in pressure drop causes a decrease of the pumping work which can be assessed in terms of $p_{3}$ to $p_{2}$ difference. Figure 10(a) shows the profile of the $p_{3}$ to $p_{2}$ difference as the DPF becomes loaded. These results correspond to the soot loading test shown in Figure 6(b). In both soot loading tests (baseline and pre-DPF water injection application), the $p_{3}$ to $p_{2}$ difference gradually increases up to $9 \mathrm{~g}$ of soot loading since $p_{2}$ is kept constant while $p_{3}$ increases due to the increasing exhaust back-pressure. From $9 \mathrm{~g}$ of soot loading on, the $p_{3}$ to $p_{2}$ difference in the baseline test keeps the rate of increase up to the end of the loading process governed by the DPF pressure drop rise. This response differs from that obtained in the case of the application of the pre-DPF water injection technique from $9 \mathrm{~g}$ of soot loading. The use of this technique allows limiting the maximum DPF pressure drop to a target value. The lack of DPF pressure drop increase gives rise to constant exhaust back-pressure $\left(p_{3}\right)$ and hence the $p_{3}$ to $p_{2}$ difference, and consequently the pumping work, remains unchanged up to the end of the test with $30 \mathrm{~g}$ of soot loading.

The profile in $p_{3}$ to $p_{2}$ difference is in agreement with the brake specific fuel consumption (bsfc) profile, which is shown in Figure 10(b) for the baseline soot loading test and in the case of pre-DPF water injection use. The initial bsfc is similar in both tests up to $9 \mathrm{~g}$ of soot loading. However it remains constant from $9 \mathrm{~g}$ to $30 \mathrm{~g}$ when the pre-DPF water injection technique is applied. Therefore, as the DPF becomes loaded the additional penalty in bsfc does not take place and the damage in fuel economy is kept equal to that corresponding to the target DPF pressure drop. At the end of the soot loading test, the bsfc is reduced in percentage around $1.35 \%$ with respect to the baseline engine operating conditions. This result is in agreement with the fact that only part of the DPF fuel penalty can be recovered controlling the maximum pressure drop.

The analysis of fuel consumption during the NEDCs carried out after the soot loading test up to $60 \mathrm{~g}$ extends the conclusions concerning fuel economy improvement to driving conditions. According to the pressure drop results shown in Figure 9(a) during a cold NEDC, the fuel consumption reduction reaches $5.2 \mathrm{~g}$ what represents a percentage reduction of 1.15\%, as shown in Figure 11(a). Immediately after the cold NEDC the engine was subjected to a second driving cycle, which is referred as hot NEDC. The accumulated fuel consumption of this test, which is shown in Figure 11(b), provides a percentage fuel consumption reduction of $0.75 \%$ when the pre-DPF water injection technique 
is applied. It is expected to obtain further bsfc savings in more dynamic cycles with higher engine load levels such as the Worldwide harmonized Light duty Test Cycle (WLTC).

The engine was also run under steady-state conditions in three low load operating points. These tests were performed just after the analysis of pressure drop under motoring conditions shown in Figure 9(b) (DPF soot loading of $30 \mathrm{~g}$ ). In order to avoid as much as possible the differences in the DPF soot loading during the test, the by-pass to the aftertreatment system (Figure 2) was used to stabilise the engine in every operating point. These are defined in Table 6 and all of them are part of the EUDC in the NEDC.

Figure 12(a) shows the DPF pressure drop as a function of the engine operating point comparing baseline conditions against the use of the pre-DPF water injection technique. As discussed in Section 4, the soot redistribution inside the inlet channels when the pre-DPF water injection is applied leads to an important reduction in pressure drop, which ranges between $30 \%$ and $40 \%$ in these operating points. This pressure drop reduction produces a decrease in the engine back-pressure that finally provides fuel saving. The comparison between the brake specific fuel consumptions shown in Figure 12(b) points out that the fuel saving, which is represented by the dashed red line, is around $1 \%$ in all tested operating points. This result agrees with the order of magnitude obtained from the NEDC tests.

\section{Analysis of DPF performance}

DPF design must ensure high filtration efficiency with low pressure drop besides good characteristics concerning regeneration capability. Being known that the pre-DPF water injection provides better pressure drop performance, this section is devoted to verify that the filtration efficiency and the regeneration dynamics maintain their nominal characteristics.

\subsection{DPF filtration efficiency}

The effect of the pre-DPF water injection on the particle emission can be divided into the instantaneous emission during the injection event and the filtration efficiency characterising the DPF during the whole soot loading test or under different operating conditions.

Figure 13(a) shows the particle number concentration during the first injection event corresponding to the soot loading test up to $30 \mathrm{~g}$ (Figure 6(b)). This is performed with a DPF soot loading equal to $9 \mathrm{~g}$. It is clearly observed that during the water residence inside the DPF monolith an increase in the particle emission is produced. The cause lies in the drag induced by the water stream on the soot particles. The maximum peak of particle number concentration is nearly two orders of magnitude higher than the nominal value before the injection event. Nevertheless, the mass of soot released during this process ( $\sim 2 \mathrm{mg}$ ) is absolutely negligible in comparison to the soot mass accumulated inside the DPF. Therefore the overall accumulated mass of soot keeps unaffected and also the filter performance.

In this sense, Figure 13(b) shows the evolution of the overall DPF filtration efficiency based on particle number concentration during the soot loading test. The first measurement of filtration efficiency was performed before the 
application of the pre-DPF water injection technique so that acts as baseline. It can be clearly observed how the DPF preserves high filtration efficiency during the soot loading test. Therefore the water injection process and its effect on the soot restructuring in the particulate layer and across the porous substrate do not have any influence on the DPF efficiency. In fact, there is a slight increase of the filtration efficiency at the end phase of the test.

A possible explanation for this response may be based on changes of the soot distribution inside the porous wall. In baseline DPF operation (without pre-DPF water injection), the soot particles penetration inside the porous wall is usually very reduced. This phenomenon has been shown by different authors covering experimental approaches, such as the works on filtration performance performed by Murtagh et al. [31], the development of new techniques for loading characterisation carried out by Fino et al. [32], the investigations of Yapaulo et al. [33] on the impact of the filtration velocity or the visual analysis of particle matter depositions presented by Liati et al. [34]. Theoretical and modelling works have also corroborated this conclusion considering meso-scale porous wall description [28] and micro-scale modelling of the flow and particles path in the porous wall [35] by using Lattice-Boltzmann techniques [36].

Therefore, according to this description, the water drag across the porous wall justifies the transient soot emission (Figure 13(a)). Nevertheless, it can also cause a slight increase of the soot mass and its penetration inside the substrate providing higher filtration efficiency of the whole monolith. On one hand, this process must involve some additional soot mass coming from the particulate layer into the porous substrate. This quantity is assumed to be small since the filtration velocity is several orders of magnitude lower than the channel velocity dragging the soot in the particulate layer towards the inlet channel end. Hence, the negligible mass of soot particles which is emitted. On the other hand, water across the porous substrate must increase the soot penetration leading to a loaded but more homogeneous substrate. According to the Darcy's law, the pressure drop of this kind of substrate is lower than that of a loaded heterogeneous porous substrate. If there are two regions, their permeabilities act as parallel resistances prevailing the region of very low permeability (soot penetration region with saturated wall) against the high permeability region (clean porous wall without soot penetration) [28]. This kind of response is also confirmed by the response of heterogeneous porous walls, which act in a similar way under clean conditions [37] but find their advantage in pressure drop in the fact that avoid soot penetration into the porous wall. Then, to reduce the pressure drop across a standard porous substrate with a given soot loading, homogeneous soot distribution is desired. Although it provides slightly higher porosity and mean pore diameter the high filtration efficiency is still ensured by the particulate layer and the more efficient use of the porous wall thickness [38].

Figure 14 shows the filtration efficiency based on the particle number concentration as a function of the particle size corresponding to the tested low load steady-state points A, B and C (Table 6). Differences between the baseline tests and the tests performed after having applied the pre-DPF water injection are negligible. The filtration efficiency profile is exactly the same including the identification of the most penetrating particle size for every operating point, which is a function of the filtration mechanisms interaction and the substrate properties. In fact, the overall filtration 
efficiency points out that there is not any influence of the pre-DPF water injection technique on the DPF filtration capability.

\subsection{DPF regeneration behaviour}

The operating point in which the DPF soot loading test was performed imposes a DPF inlet temperature $\left(\sim 325^{\circ} \mathrm{C}\right)$ high enough to promote passive regeneration as the soot loading increases. Although the soot loading and pressure drop increase are not avoided, the analysis of the $\mathrm{NO}_{\mathrm{x}}$ emission reveals that some soot particles are burnt out because of $\mathrm{NO}_{2}$ presence.

Figure 15 shows the evolution of the tailpipe $\mathrm{NO}_{2}$ and $\mathrm{NO}$ fraction throughout the soot loading test performed up to $30 \mathrm{~g}$ (Figure 6(b)). The results corresponding to the baseline configuration and the application of the pre-DPF water injection technique are both represented. Despite the small differences in total $\mathrm{NO}_{\mathrm{x}}$ fraction, the $\mathrm{NO}_{2}$ and $\mathrm{NO}$ trend is the same in both tests, without influence of the pre-DPF water injection use. At the beginning of the test, the thermal transient of the engine leads to an increasing $\mathrm{NO}_{2}$ fraction and to the corresponding NO decrease. These fractions stabilise and remain almost constant up to a soot loading of $3 \mathrm{~g}$. From this moment, the $\mathrm{NO}_{2}$ fraction begins to decrease slightly while NO increases complementary. Considering that the engine is operating under steady-state conditions, this result clearly indicates that soot oxidation by $\mathrm{NO}_{2}$ is taking place.

In the case of the soot loading test with pre-DPF water injection application, this is applied from $9 \mathrm{~g}$ in soot loading. It can be observed that there is not any relevant change in $\mathrm{NO}_{2}$ and $\mathrm{NO}$ fraction, which has in fact the same slope as in the baseline test. It indicates that the use of consecutive pre-DPF water injection events has not any effect on passive regeneration capability because of the soot restructuring. Concerning this point it is also of interest to indicate that the injection of water in the exhaust gas stream produces a transitory increase of the water volume fraction. As observed in Figure 16, which corresponds to the first injection event of the soot loading test up to $30 \mathrm{~g}$, the tailpipe water fraction experiments a sudden increase related to the water injection event whose maximum peak doubles the nominal value. From this peak the water fraction recovers back the nominal value controlling the thermal transient process. Although the nominal water fraction in the tailpipe $(7.5 \%)$ is several orders of magnitude higher than the $\mathrm{NO}_{2}$ fraction $(\sim 120 \mathrm{ppm})$ the transitory rise of water fraction may lead to a slight increase of the formation of traces of nitric and nitrous acids in the exhaust gas. Several authors have observed that the increase of water in the exhaust gas enhances the reaction of soot with $\mathrm{NO}_{2}$ without modifying the global mechanism. As discussed by Jeguirim et al. [39] it is attributed to the indicated potential formation of nitric and nitrous acids in presence of water and $\mathrm{O}_{2}$. This was also pointed out by Kirchner et al. [40], who observed an increase in C-ONO2 and C-ONO groups in the reaction of soot when nitric acid is present in the exhaust flow. In the same way, Uchisawa et al. [41] found the cause of the soot oxidation improvement due to water presence in the strong acidity produced by hydrolysis and decarboxylation, as also indicated by Ciambelli et al. [42].

The lack of relevant influence of pre-DPF water injection on passive regeneration is also found during active regeneration. Figure 17 shows the pressure drop and gas temperature during an active regeneration based on late 
fuel injection. The initial DPF soot loading is $30 \mathrm{~g}$. Figure 17(a) confirms that during the regeneration the pressure drop profile is similar in both tests confirming the same dynamics of the process. This result is obtained even with lower inlet gas temperature in the case of previous pre-DPF water injection. The consequence is a lower outlet gas temperature during the test although keeping the same trend and leading to a similar maximum outlet temperature.

Passive and active regeneration results evidence that the change in soot distribution in the particulate layer and inside the porous substrate is only affecting the DPF performance regarding pressure drop. On one hand, it means that there are not produced changes in the particulate matter properties able to influence the oxidation rate. On the other hand, the hypothesised drag of particles towards the inlet channel end or its higher penetration into the porous wall may lead to the modification of the contact surface of soot and $\mathrm{O}_{2} / \mathrm{NO}_{2}$. However, this property has been shown not to be critical in the tested range, in which the oxidation rate seems to be more dependent on soot properties, temperature and oxidant content.

\section{Summary and conclusions}

This paper has presented a novel technique based on pre-DPF water injection to reduce the pressure drop under soot or ash loading conditions. A proper management of the injection events allows controlling the pressure drop produced by the DPF independently of the loading level. This makes possible to control the fuel consumption penalty that the DPF use involves.

Although the work is devoted to the study of the influence of this technique on the overall engine and DPF performance, the analysis of the obtained results indicates that the DPF pressure drop reduction can be caused by two main phenomena. On one hand, it is supposed to be produced by the drag of the soot on the particulate layer towards the end of the inlet channels. Thus it provides regions of reduced particulate layer thickness giving rise to a new filtration velocity profile. The combination of these properties produces lower pressure drop. On the other hand, soot inside the porous wall may be restructured along its thickness increasing the porous wall permeability and favouring a further pressure drop reduction.

The comparison of the baseline tests under different engine operating conditions against the pre-DPF water injection use has revealed the robustness of this technique. During soot loading processes the pressure drop can be controlled with consecutive water injections. Although there is a lack of analysis on the injection pressure and other geometrical parameters that may affect the required quantity of injected water mass, the minimum effective quantity of injected water mass in every event was found to be $200 \mathrm{~g}$. The control of pressure drop is estimated to require $1 \mathrm{~kg}$ of injected water every 13.25 NEDCs. It corresponds to an average water consumption of $0.23 \mathrm{~kg} / \mathrm{h}$.

As the number of injection events increases a loss of effectiveness of the process has been observed. This can be overcome by means of a small increase in the target pressure drop. It allows extending the DPF loading process up to the critical soot mass with constant pressure drop. Consequently, the control of the active regeneration comes only dependent on the soot mass and the influence of the pressure drop completely disappears. This means that the loading 
capability of the DPF increases as it is only depending on the soot mass limit for safe regeneration. With the same approach, the DPF maintenance due to ash loading becomes independent of the pressure drop increase because of its collection. The higher loading capability can be moved from higher soot loading to higher ash loading during the DPF timelife. To operate in this way the DPF control would impose more frequent water injections (less soot loading between injections) and active regeneration to compensate the effect of the ash loading increase.

In terms of fuel economy improvement, the different tests described in this work indicate potential for fuel consumption reduction ranging around $1 \%$. The final improvement depends on the engine operating conditions, the target DPF pressure drop as a function of the operating conditions and the maximum allowable soot mass without compromising the DPF durability due to an excessive peak of temperature during regeneration, i.e. in the reduction of the required number of active regenerations per unit of time. The reduction in fuel consumption provides a clear advantage in $\mathrm{CO}_{2}$ emission reduction. Nevertheless efforts should be driven to reduce the quantity of water consumption based on the optimization of the injection settings. It would improve the cost competitiveness of the technique. With regards to other DPF characteristics, no influence on the overall filtration efficiency has been found. The water drag during the injection event does not produce soot release causing the DPF pressure drop. Measurements demonstrate that the soot release during this process is negligible in comparison to the soot loading and without effect on the capability to fulfil emission standards. In a similar way, the capability for active and passive regeneration without change on the process dynamics has been proved.

\section{Acknowledgements}

This work has been partially supported by the Spanish Ministry of Economy and Competitiveness through Grant No. TRA2013-40853-R.

[1] Johnson TV. Diesel emission control in review, Int J Engine Res 2009;10:275-85.

[2] Choi Y, Dang Z, Stone R, Morrill M, Floyd D. New flow-through trap system targeting 50\% PM removal for diesel emission control, in: SAE Technical Paper 2007-04-16, 2007

[3] Heck RM, Farrauto RJ. Catalytic air pollution control, Commercial Technology, Hoboken, New Jersey: John Wiley \& Sons Inc.; 2009.

[4] Serrano JR, Climent H, Piqueras P, Angiolini E. Analysis of fluid-dynamic guidelines in diesel particulate filter sizing for fuel consumption reduction in post-turbo and pre-turbo placement, Appl Energ 2014;132:507-23.

[5] Bermúdez V, Serrano JR, Piqueras P, García-Afonso O. Analysis of heavy-duty turbocharged diesel engine response under cold transient operation with a pre-turbo aftertreatment exhaust manifold configuration, Int J Engine Res 2013;14(4):341-53.

[6] Bermúdez V, Serrano JR, Piqueras P, García-Afonso O. Influence of DPF soot loading on engine performance with a pre-turbo aftertreatment exhaust line, in: SAE Technical Paper 2012-01-0362, 2012.

[7] Lapuerta M, Rodríguez-Fernández J, Oliva F. Effect of soot accumulation in a diesel particle filter on the combustion process and gaseous emissions, Energy 2012;47:543-52.

[8] Gaiser G, Mucha P. Prediction of pressure drop in diesel particulate filters considering ash deposit and partial regeneration, in: SAE Technical Paper 2004-01-0158, 2004.

[9] Sappok A, Wong V. Ash effects on diesel particulate filter pressure drop sensitivity to soot and implications for regeneration frequency and DPF control, SAE Int J Fuels Lubr 2010;3:380-96. 
[10] Wang Y, Wong V, Sappok A, Munnis S. The sensitivity of DPF performance to the spatial distribution of ash inside DPF inlet channels, in: SAE Technical Paper 2013-01-1584, 2013.

[11] Sappok A, Govani I, Kamp C, Wang Y, Wong V. In-situ optical analysis of ash formation and transport in diesel particulate filters during active and passive regeneration processes, SAE Int J Fuels Lubr 2013;6:336-49.

[12] Dittler A. Ash transport in diesel particulate filters, in: SAE Technical Paper 2012-01-1732, 2012.

[13] Fino D, Specchia V. Open issues in oxidative catalysis for diesel particulate abatement, Powder Technol 2008;180:64-73.

[14] Kotrba A, Gardner TP, Bai L, Yetkin A. Passive regeneration response characteristics of a DPF system, in: SAE Technical Paper 2013-04-08, 2013.

[15] Song J, Wang J, Boehman AL. The role of fuel-borne catalyst in diesel particulate oxidation behavior, Combust Flame 2006;146:73-84.

[16] Kirkpatrick MJ, Odic E, Zinola S, Lavy J. Plasma assisted heterogeneous catalytic oxidation: HCCI diesel engine investigations, Appl Catal B-Environ 2012;117:1-9.

[17] Kuwahara T, Nishii S, Kuroki T, Okubo M. Complete regeneration characteristics of diesel particulate filter using ozone injection, Appl Energ 2013;111:652-56.

[18] Dilip KV, Vasa NJ, Carsten K, Ravindra KU. Incineration of diesel particulate matter using induction heating technique, Appl Energ 2011;88:938-46.

[19] Beatrice C, Di Iorio S, Guido C, Napolitano P. Detailed characterization of particulate emissions of an automotive catalyzed DPF using actual regeneration strategies, Exp Therm Fluid Sci 2012;39:45-53.

[20] Tourlonias P, Koltsakis GC. Model-based comparative study of Euro 6 diesel aftertreatment concepts, focusing on fuel consumption, Int J Engine Res 2011;12:238-51.

[21] Stamatelos AM. A review of the effect of particulate traps on the efficiency of vehicle diesel engines, Energ Conver Manage 1997;38:83-99.

[22] Noguchi S, Sogawa Y, Kawaguchi H, Kono N. A quantitative study of fuel efficiency of diesel vehicles with diesel particulate filter in repeated test cycles, in: SAE Technical Paper 2012-01-1704, 2012.

[23] Lee SJ, Jeong SJ, Kim WS. Numerical design of the diesel particulate filter for optimum thermal performances during regeneration, Appl Energ 2009;86:1124-35.

[24] Song B, Choi Y. Investigation of variations of lubricating oil diluted by post-injected fuel for the regeneration of CDPF and its effects on engine wear, J Mech Sci Technol 2008;22:2526-33.

[25] Konstandopoulos AG, Kostoglou M, Vlachos N, Kladopoulou E. Advances in the science and technology of diesel particulate filter simulation, Adv Chem Eng 2007;33:213-75,284-94.

[26] Chen K, Martirosyan KS, Luss D. Temperature gradients within a soot layer during DPF regeneration, Chem Eng Sci 2011;66:2968-73.

[27] Singh N, Rutland CJ, Foster DE, Narayanaswamy K, He Y. Investigation into different DPF regeneration strategies based on fuel economy using integrated system simulation, in: SAE Technical Paper 2009-01-1275, 2009.

[28] Serrano JR, Arnau FJ, Piqueras P, García-Afonso O. Packed bed of spherical particles approach for pressure drop prediction in wall-flow DPFs (diesel particulate filters) under soot loading conditions, Energy 2013;58:644-54.

[29] Desantes JM, Payri F, Piqueras P, Serrano JR. Sistema de filtro de partículas para motor y método de reducción de pérdida de presión de dicho filtro, Spanish Patent ES2408243(B1), 2013.

[30] Torregrosa AJ, Serrano JR, Arnau FJ, Piqueras P. A fluid dynamic model for unsteady compressible flow in wall-flow diesel particulate filters, Energy 2011;36:671-84.

[31] Murtagh MJ, Sherwood DL, Socha LS. Development of a diesel particulate filter composition and its effect on thermal durability and filtration performance, in: SAE Technical Paper 940235, 1994.

[32] Fino D, Russo N, Millo F, Vezza DS, Ferrero F, Chianale A. New tool for experimental analysis of diesel particulate filter loading, Top Catal 2009;52:13-20.

[33] Yapaulo RA, Wirojsakunchai E, Orita T, Foster DE, Akard M, Walker LR, Lance MJ, Impact of filtration velocities and particulate matter characteristics on diesel particulate filter wall loading, Int J Engine Res 2009;10(5):287-304. 
[34] Liati A, Eggenschwiler PD. Characterization of particulate matter deposited in diesel particulate filters: Visual and analytical approach in macro-, micro- and nano-scales, Combust Flame 2010;157:1658-70.

[35] Stewart ML, Gallant TR, Kim DH, Maupin GD, Zelenyuk A. Fuel efficient diesel particulate filter (DPF) modeling and development, in: Pacific Northwest National Laboratory, PNNL-19476, USA, 2010.

[36] Yamamoto K, Oohori A, Yamashita H, Daido S. Simulation on soot deposition and combustion in diesel particulate filter, Proc Combust Inst 2009;32:1965-72.

[37] Bollerhoff T, Markomanolakis I, Koltsakis G. Filtration and regeneration modeling for particulate filters with inhomogeneous wall structure, Catal Today 2012;188:24-31.

[38] Tandon P, Heibel A, Whitmore J, Kekre N, Chithapragada K. Measurement and prediction of filtration efficiency evolution of soot loaded diesel particulate filters, Chem Eng Sci 2010;65:4751-560.

[39] Jeguirim M, Tschamber V, Brilhac JF, Ehrburger P. Oxidation mechanism of carbon black by $\mathrm{NO}_{2}$ : Effect of water vapour, Fuel 2005;84:19491956.

[40] Kirchner U, Scheer V, Vogt R. FTIR Spectroscopic Investigation of the Mechanism and Kinetics of the Heterogeneous Reactions of NQ and $\mathrm{HNO}_{3}$ with Soot, J Phys Chem A 2000;104:8908-15.

[41] Uchisawa JO, Obuchi A, Ogata A, Enomoto R, Kushiyama S. Effect of feed gas composition on the rate of carbon oxidation with Pt/SiQ and the oxidation mechanism, Appl Catal B 1999;21:9-17.

[42] Ciambelli P, Palma V, Russo P, Vaccaro S. The role of NO in the regeneration of catalytic ceramic filters for soot removal from exhaust gases, Catal Today 2000;60:43-9.

\section{Nomenclature}

$\begin{array}{ll}\text { Abbreviations } & \\ \text { bsfc } & \text { break specific fuel consumption } \\ \text { DPF } & \text { diesel particulate filter } \\ \text { DOC } & \text { diesel oxidation catalyst } \\ \text { E } & \text { DPF filtration efficiency } \\ \text { ECU } & \text { electronic control unit } \\ \text { EUDC } & \text { extra urban driving cycle } \\ \text { HWFET } & \text { Highway Fuel Economy Test } \\ \text { NEDC } & \text { New European Driving Cycle } \\ p_{2} & \text { boosting pressure } \\ p_{3} & \text { turbine inlet pressure } \\ \text { TMG-2 } & \text { Tokyo Metropolitan Government driving cycle 2 } \\ \text { WLTC } & \text { Worldwide harmonized Light duty Test Cycle }\end{array}$

\section{List of Tables}

- Table 1.- Basic engine characteristics.

- Table 2.- Wall-flow DPF characteristics.

- Table 3.- Characteristics of the instrumentation. 
- Table 4.-Injection rate and duration as a function of the injected water mass.

- Table 5.- Injection rate and duration as a function of the nozzle diameter.

- Table 6.- Definition of the low load steady-state operating points.

\section{List of Figures}

- Figure 1.- Scheme of DPF pressure and temperature instrumentation setup.

- Figure 2.- By-pass valve system to control DPF soot accumulation during engine stabilisation.

- Figure 3.- Pressure drop limit as a function of the volumetric flow rate at DPF inlet for active regeneration initiation in the tested engine.

- Figure 4.- Effect of the quantity of injected water mass on the DPF pressure drop.

- Figure 5.- Effect of the injector nozzle diameter on the DPF pressure drop.

- Figure 6.- Comparison in DPF pressure drop between the baseline configuration and the use of the pre-DPF water injection technique during the soot loading tests.

- Figure 7.- Comparison between the first and the third water injection events during the soot loading test with application of pre-DPF water injection from $9 \mathrm{~g}$ in soot loading.

- Figure 8.- Evolution of the soot loading between consecutive injection events and target pressure drop throughout the soot loading test with application of pre-DPF water injection from $9 \mathrm{~g}$ in soot loading.

- Figure 9.- Comparison in DPF pressure drop between the baseline configuration and the use of the pre-DPF water injection technique under NEDC and motoring operating conditions.

- Figure 10.- Comparison of the engine back-pressure and bsfc evolution throughout a DPF soot loading test between the baseline configuration and the use of the pre-DPF water injection technique.

- Figure 11.- Comparison in fuel consumption between the baseline configuration and the use of the pre-DPF water injection technique during cold and hot NEDCs.

- Figure 12.- Comparison in DPF pressure drop and fuel consumption between the baseline configuration and the use of the pre-DPF water injection technique under low load steady-state operating conditions with $30 \mathrm{~g}$ of DPF soot loading.

- Figure 13.- Pre-DPF water injection effect on DPF filtration efficiency during a soot loading test.

- Figure 14.- Pre-DPF water injection effect on filtration efficiency under different steady-state operating conditions.

- Figure 15.- Comparison of the $\mathrm{NO}$ and $\mathrm{NO}_{2}$ tailpipe fraction during the soot loading process between the baseline configuration and the use of the pre-DPF water injection technique.

- Figure 16.- Tailpipe water volume fraction during the first injection event in the soot loading test up $30 \mathrm{~g}$.

- Figure 17.- Comparison of the DPF response under active regeneration conditions between the baseline configuration and the use of the pre-DPF water injection technique. 
Table 1: Basic engine characteristics.

\begin{tabular}{ll}
\hline \multicolumn{2}{c}{ Table 1: Basic engine characteristics. } \\
\hline \hline Type & HSDI Diesel passenger car \\
Emission standards & EURO 4 \\
Displacement & $1997 \mathrm{~cm}^{3}$ \\
Bore & $85 \mathrm{~mm}$ \\
Stroke & $88 \mathrm{~mm}$ \\
Number of cylinders & 4 in line \\
Number of valves & 4 per cylinder \\
Compression ratio & $18: 1$ \\
Maximum power @ speed & $100 \mathrm{~kW} @ 4000 \mathrm{rpm}$ \\
Maximum torque @ speed & $320 \mathrm{Nm} @ 1750 \mathrm{rpm}$ \\
\hline \hline
\end{tabular}

Table 2: Wall-flow DPF characteristics.

\begin{tabular}{lcc}
\hline \hline Diameter & {$[\mathrm{mm}]$} & 132 \\
Length & {$[\mathrm{mm}]$} & 200 \\
Plug length & {$[\mathrm{mm}]$} & 3.2 \\
Volume & {$[1]$} & 2.73 \\
Specific permeability & {$\left[\mathrm{m}^{2}\right]$} & $2.49 \times 10^{-13}$ \\
Cell density & {$[\mathrm{cpsi}]$} & 200 \\
Honeycomb cell size & {$[\mathrm{mm}]$} & 1.486 \\
Wall thickness & {$[\mathrm{mm}]$} & 0.31 \\
Noof channels & {$[-]$} & 4246 \\
Filtration area & {$\left[\mathrm{m}^{2}\right]$} & 2.5 \\
Porosity & {$[-]$} & 0.41 \\
Mean pore diameter & {$[\mu m]$} & 12.1 \\
Inlet cone volume & {$[1]$} & 0.5 \\
Outlet cone volume & {$[\mathrm{l}]$} & 0.45 \\
\hline \hline
\end{tabular}


Table 3: Characteristics of the instrumentation.

\begin{tabular}{llll}
\hline \hline \multicolumn{1}{c}{ Magnitude } & \multicolumn{1}{c}{ Sensor/Instrument } & \multicolumn{1}{c}{ Range } & \multicolumn{1}{c}{ Error } \\
\hline Temperature & Thermocouple Type K & {$\left[-200-1,200^{\circ} \mathrm{C}\right]$} & $\pm 1.1^{\circ} \mathrm{C}$ or $0.4 \%$ (actual value) \\
Mean pressure & Piezoresistive PMA P40 & {$[0-6 \mathrm{bar}]$} & $\pm 0.3 \%$ (full scale) \\
Fuel mass flow & Gravimetric balance & {$[0-27 \mathrm{~kg} / \mathrm{h}]$} & $\pm 0.12 \%$ (full scale) \\
Air mass flow & Sensyflow & {$[0-720 \mathrm{~kg} / \mathrm{h}]$} & $\pm 1 \%$ (actual value) \\
Torque & Torquimeter & {$[-650-650 \mathrm{Nm}]$} & $\pm 0.1 \%$ (full scale) \\
\hline \hline
\end{tabular}

Table 4: Injection rate and duration as a function of the injected water mass

\begin{tabular}{cccccc}
\hline \hline Injected water mass & {$[\mathrm{g}]$} & 200 & 110 & 85 & 40 \\
\hline Nozzle diameter & {$[\mathrm{mm}]$} & 4 & 4 & 4 & 4 \\
Injection rate & {$[\mathrm{g} / \mathrm{s}]$} & 66 & 66 & 66 & 66 \\
Injection duration & {$[\mathrm{s}]$} & 3 & 1.6 & 1.3 & 0.6 \\
\hline \hline
\end{tabular}

Table 5: Injection rate and duration as a function of the nozzle diameter.

\begin{tabular}{ccccc}
\hline \hline Nozzle diameter & {$[\mathrm{mm}]$} & 4 & 2.7 & 1 \\
\hline Injected water mass & {$[\mathrm{g}]$} & 200 & 200 & 200 \\
Injection rate & {$[\mathrm{g} / \mathrm{s}]$} & 66 & 18 & 9 \\
Injection duration & {$[\mathrm{s}]$} & 3 & 11 & 22 \\
\hline \hline
\end{tabular}

Table 6: Definition of the low load steady-state operating points.

\begin{tabular}{lccc}
\hline \hline Point & $\begin{array}{c}\text { Speed } \\
{[\mathrm{rpm}]}\end{array}$ & $\begin{array}{c}\text { Load } \\
{[\%]}\end{array}$ & $\begin{array}{c}\text { EGR rate } \\
{[\%]}\end{array}$ \\
\hline A & 1580 & 15.7 & 36.5 \\
B & 1660 & 34.1 & 14 \\
C & 2240 & 32.2 & 13 \\
\hline \hline
\end{tabular}




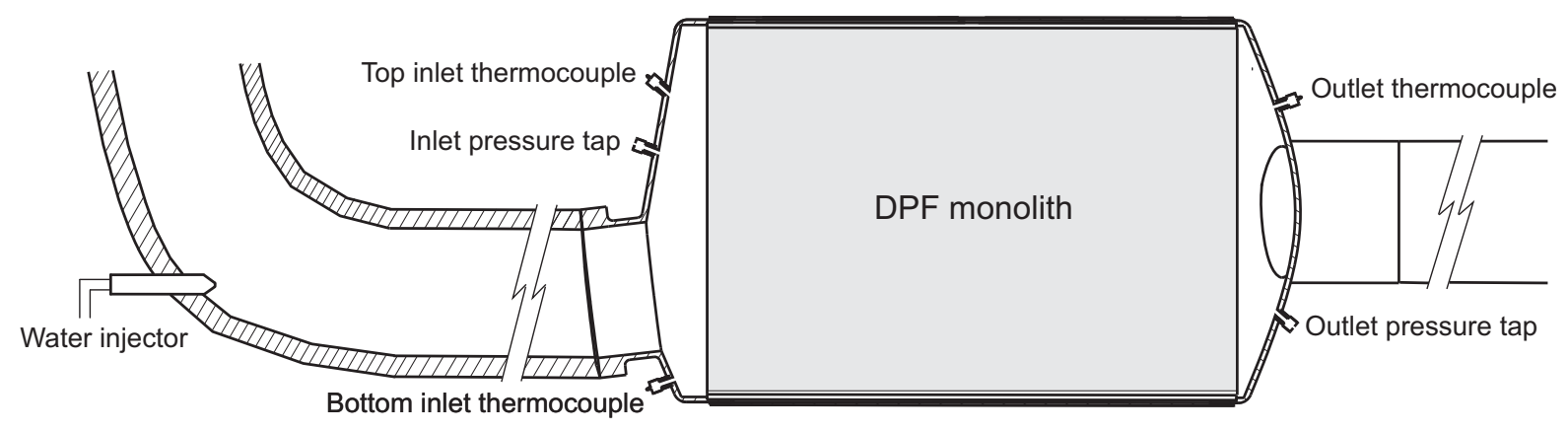

Figure 1: Scheme of DPF pressure and temperature instrumentation setup.

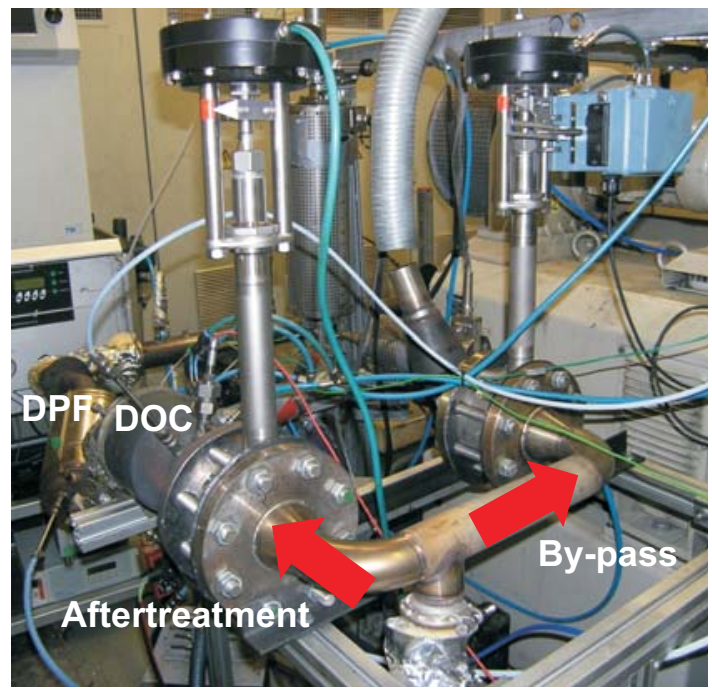

Figure 2: By-pass valve system to control DPF soot accumulation during engine stabilisation.

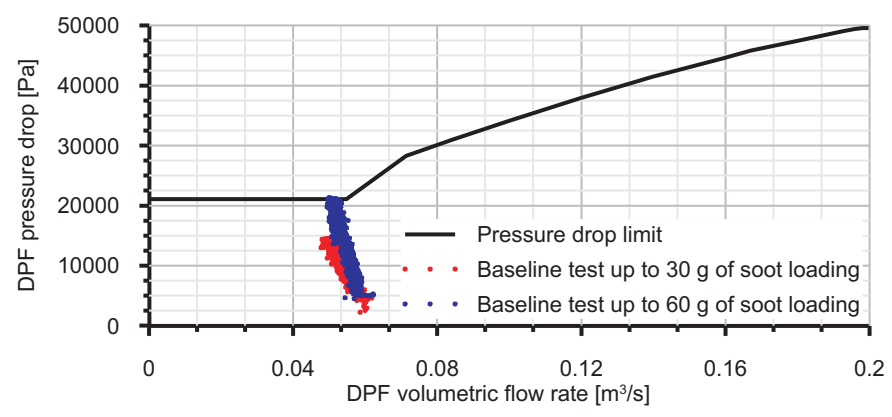

Figure 3: Pressure drop limit as a function of the volumetric flow rate at DPF inlet for active regeneration initiation in the tested engine. 

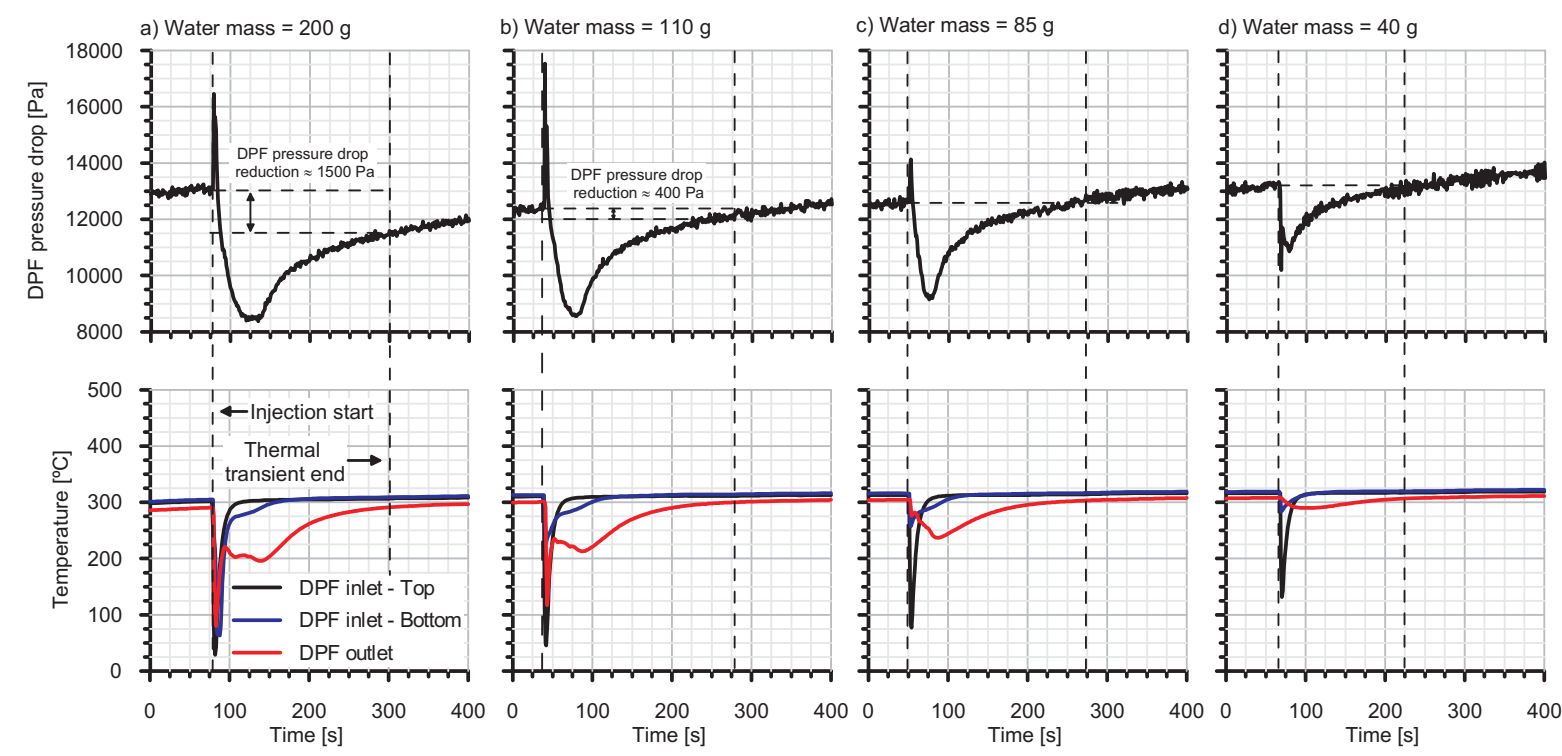

Figure 4: Effect of the quantity of injected water mass on the DPF pressure drop.
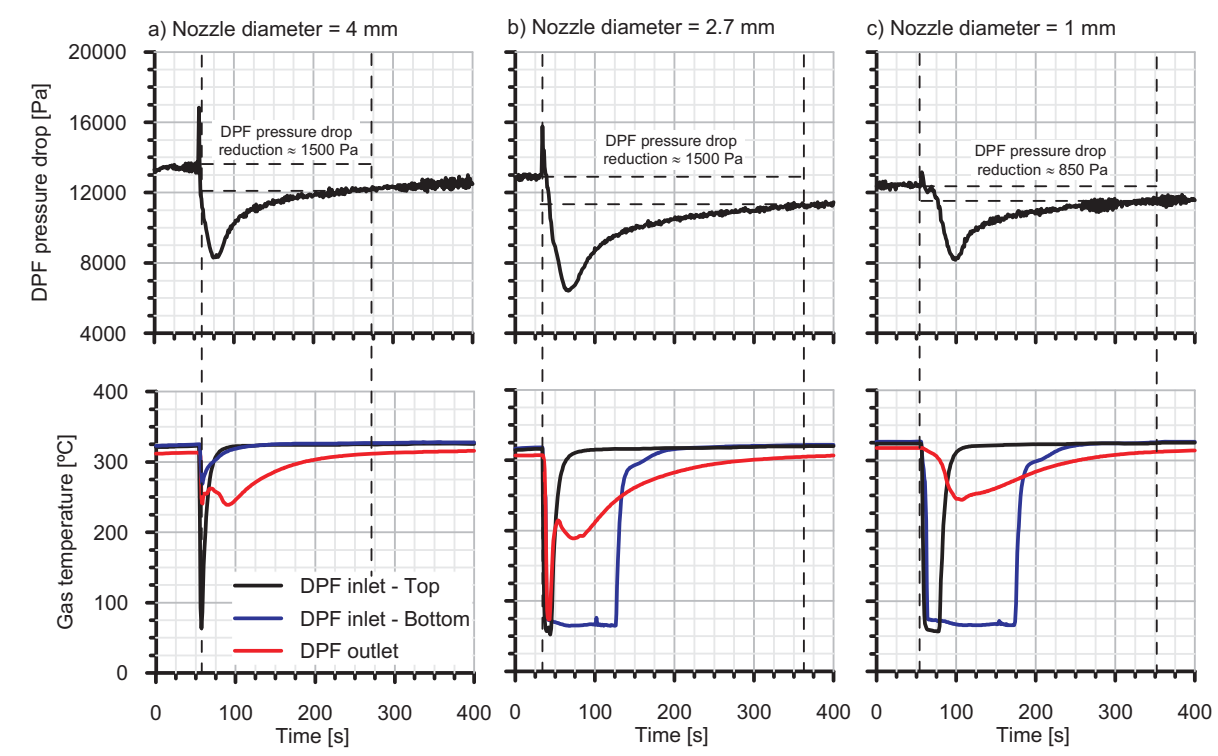

Figure 5: Effect of the injector nozzle diameter on the DPF pressure drop. 

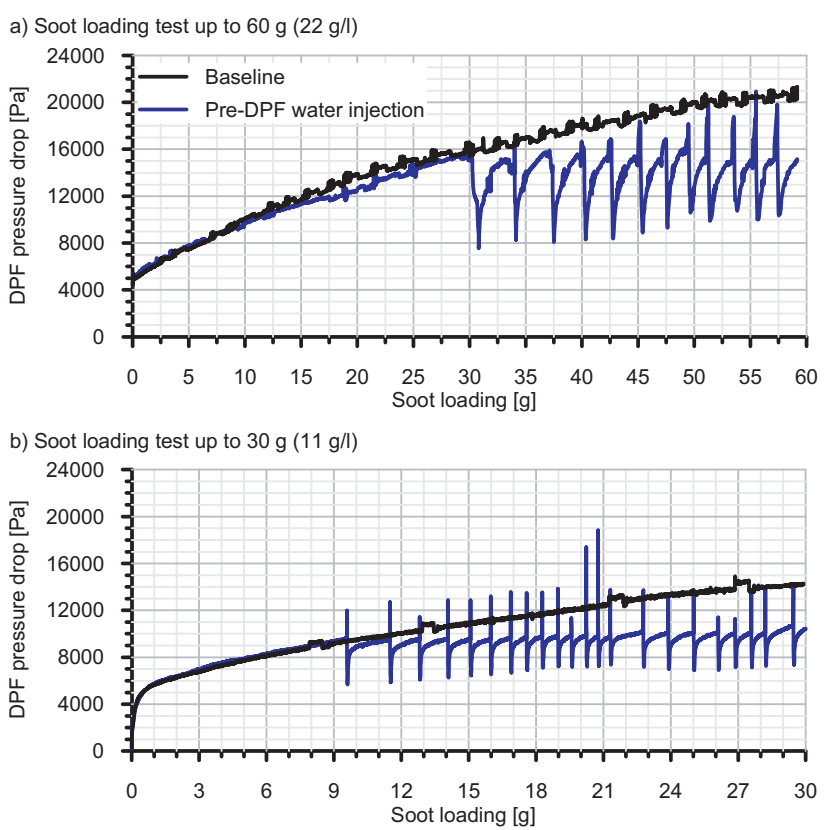

Figure 6: Comparison in DPF pressure drop between the baseline configuration and the use of the pre-DPF water injection technique during the soot loading tests.

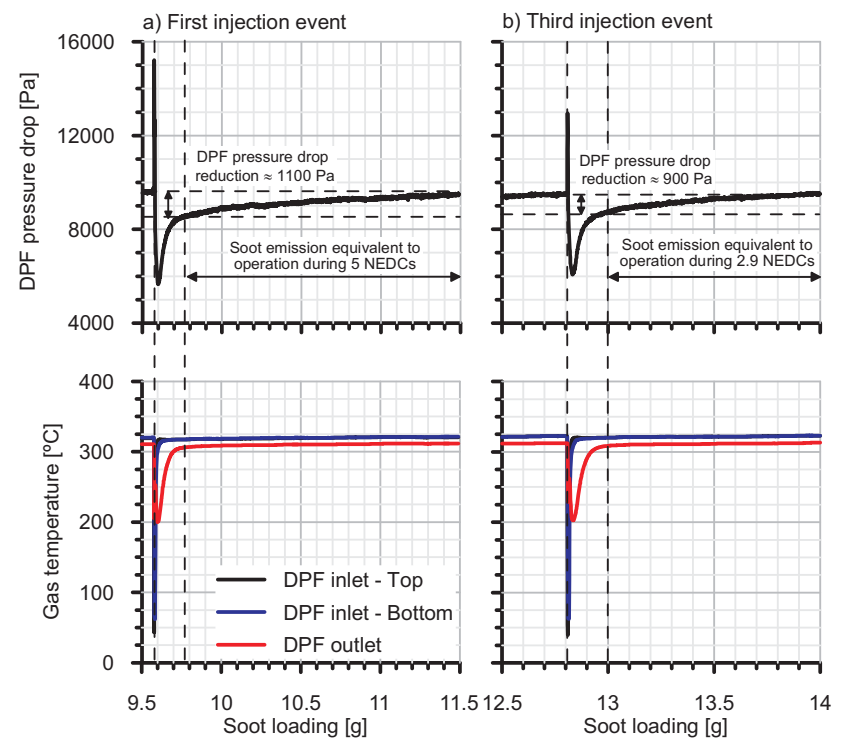

Figure 7: Comparison between the first and the third water injection events during the soot loading test with application of pre-DPF water injection from $9 \mathrm{~g}$ in soot loading. 


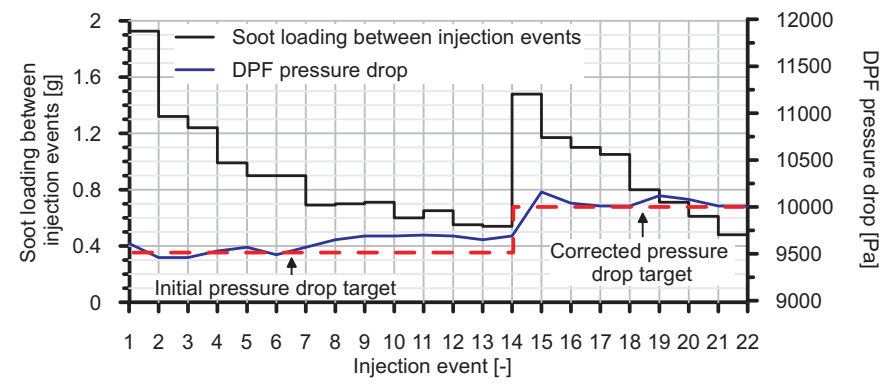

Figure 8: Evolution of the soot loading between consecutive injection events and target pressure drop throughout the soot loading test with application of pre-DPF water injection from $9 \mathrm{~g}$ in soot loading.
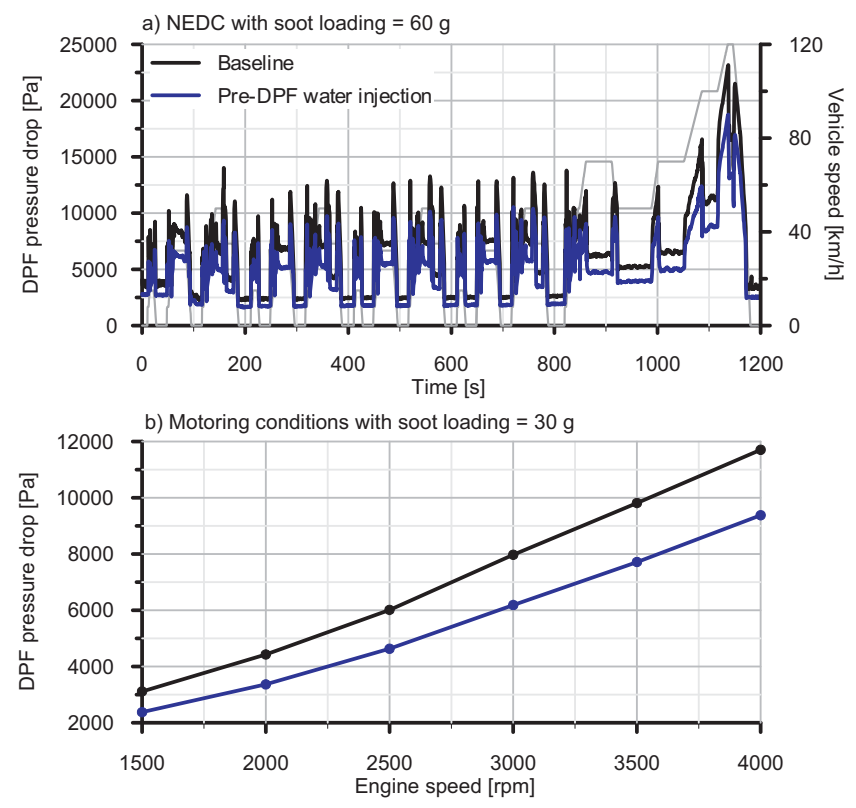

Figure 9: Comparison in DPF pressure drop between the baseline configuration and the use of the pre-DPF water injection technique under NEDC and motoring operating conditions. 


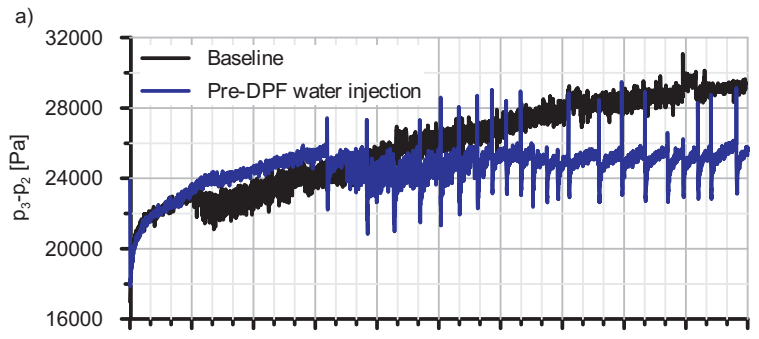

b)

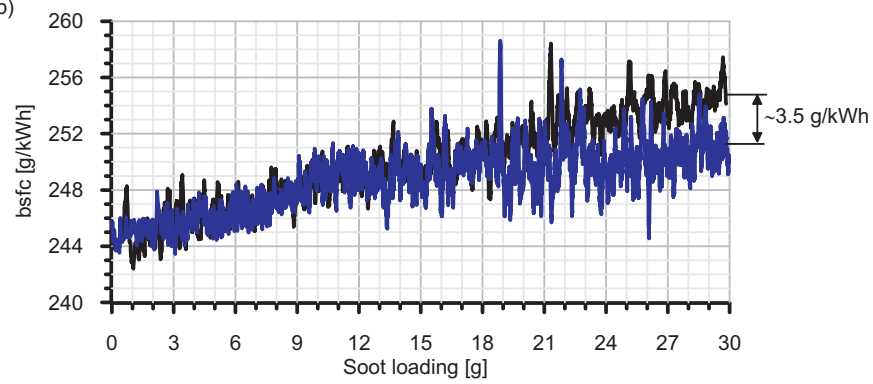

Figure 10: Comparison of the engine back-pressure and bsfc evolution throughout a DPF soot loading test between the baseline configuration and the use of the pre-DPF water injection technique.
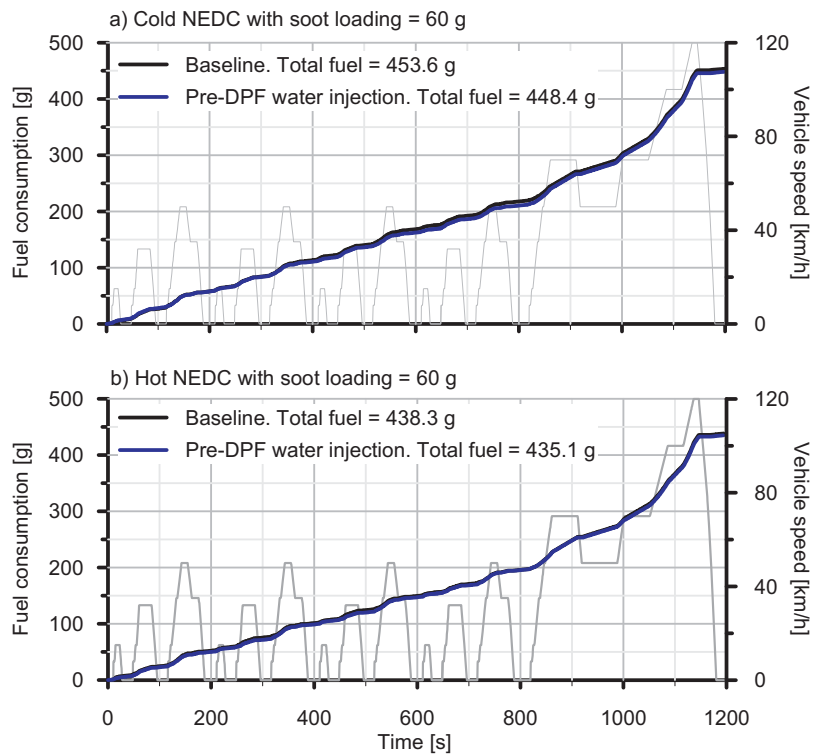

Figure 11: Comparison in fuel consumption between the baseline configuration and the use of the pre-DPF water injection technique during cold and hot NEDCs. 

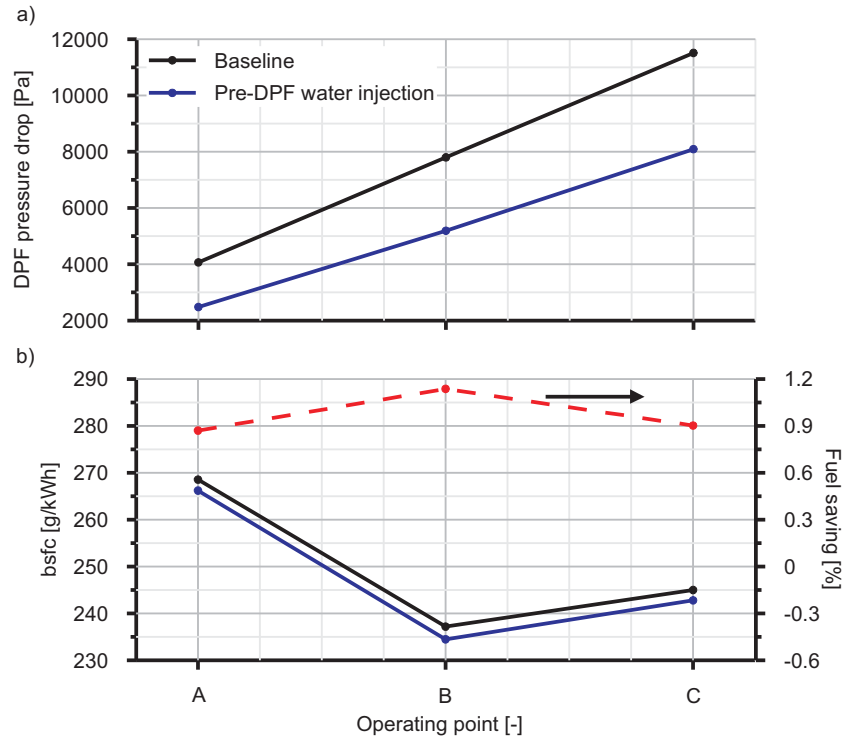

Figure 12: Comparison in DPF pressure drop and fuel consumption between the baseline configuration and the use of the pre-DPF water injection technique under low load steady-state operating conditions with $30 \mathrm{~g}$ of DPF soot loading.
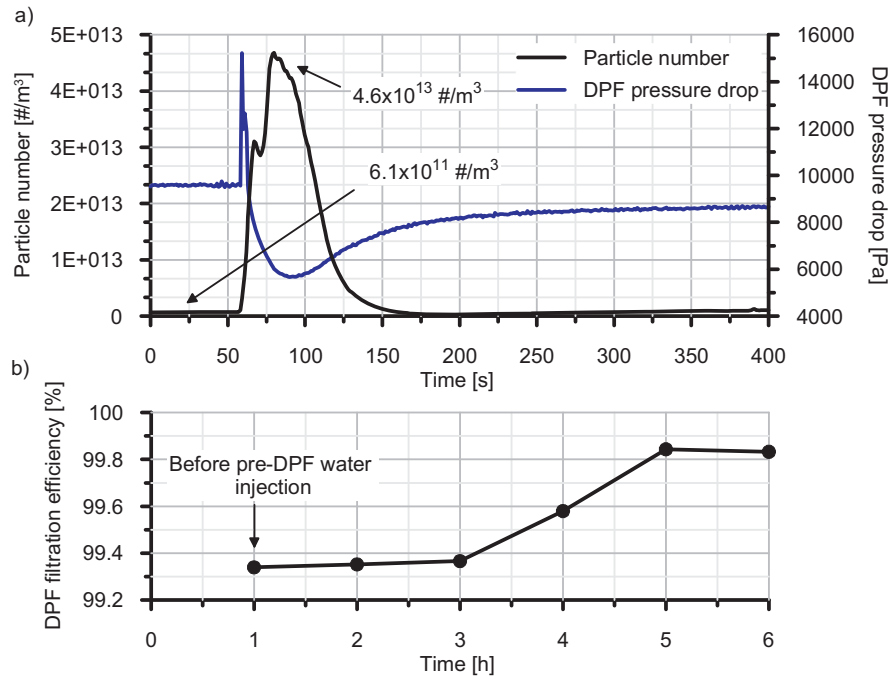

Figure 13: Pre-DPF water injection effect on DPF filtration efficiency during a soot loading test. 


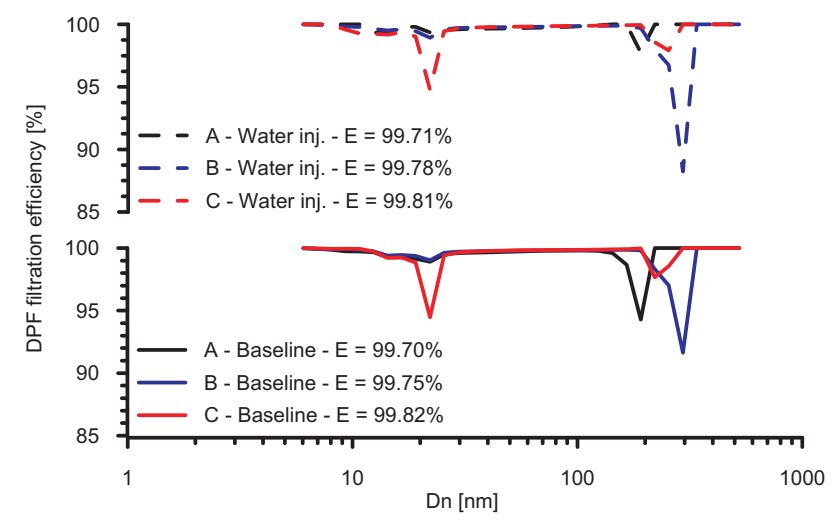

Figure 14: Pre-DPF water injection effect on filtration efficiency under different steady-state operating conditions.

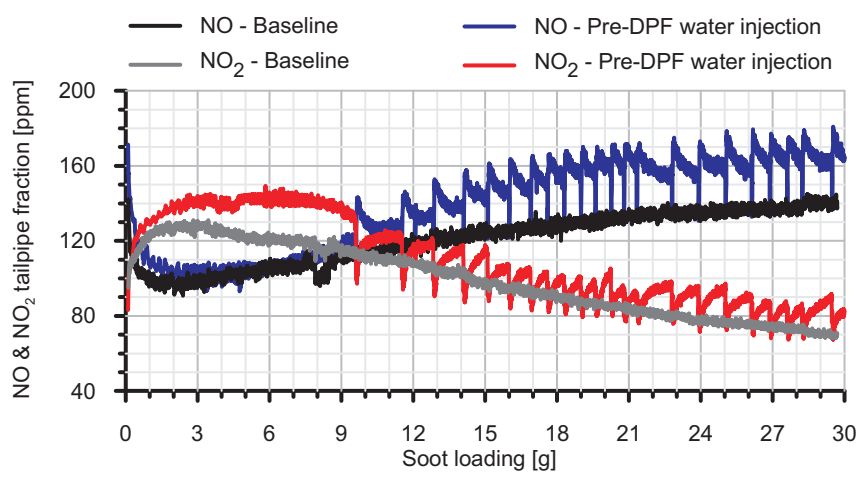

Figure 15: Comparison of the $\mathrm{NO}$ and $\mathrm{NO}_{2}$ tailpipe fraction during the soot loading process between the baseline configuration and the use of the pre-DPF water injection technique.

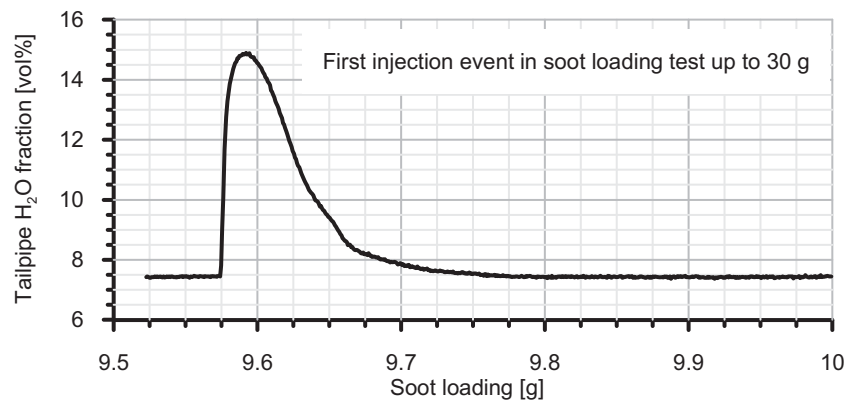

Figure 16: Tailpipe water volume fraction during the first injection event in the soot loading test up $30 \mathrm{~g}$. 

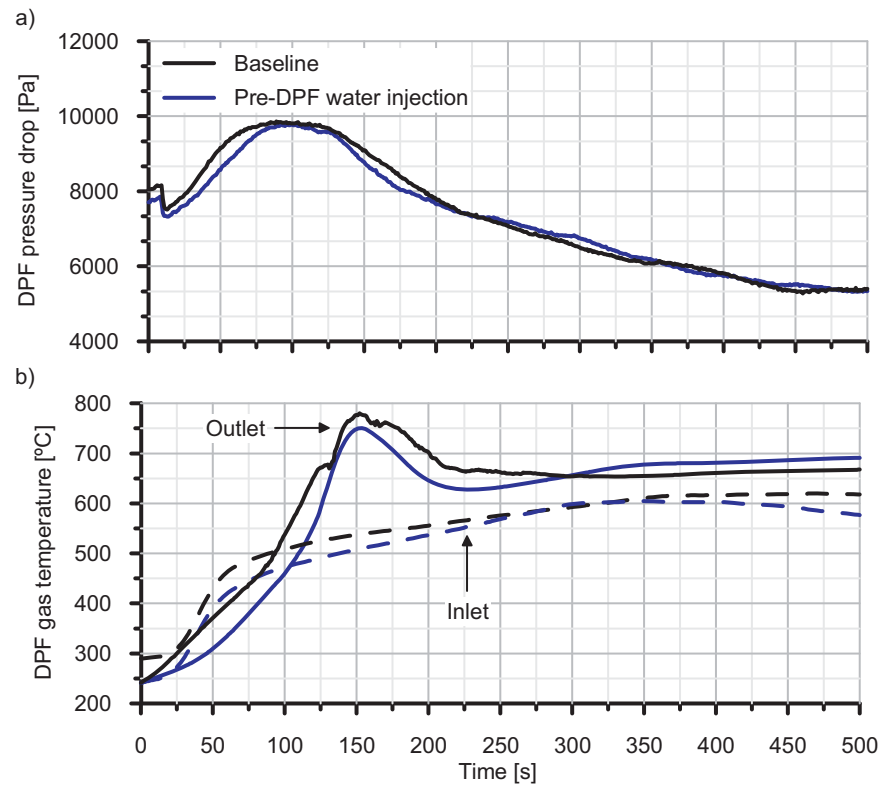

Figure 17: Comparison of the DPF response under active regeneration conditions between the baseline configuration and the use of the pre-DPF water injection technique. 